\title{
Hepatitis B Virus X Protein Reduces Podocyte Adhesion via Downregulation of $\alpha 3 \beta 1$ Integrin
}

\author{
Ping He Dajun Liu Beiru Zhang Guangyu Zhou Xuesong Su Yanqiu Wang \\ Xu Yang Detian Li \\ Department of Nephrology, Shengjing Hospital of China Medical University, Shenyang, P.R. China
}

\section{Key Words}

$\mathrm{HBx} \bullet$ Podocyte $\bullet$ Cell adhesion $\bullet$ Apoptosis $\bullet \alpha 3 \beta 1$ integrin

\begin{abstract}
Background/Aims: Hepatitis B virus (HBV)-associated glomerulonephritis (HBV-GN) is characterized by a reduced number of podocytes due to apoptosis and shedding from the basement membrane. However, the pathological mechanism of HBV-GN is unclear. We previously showed that hepatitis $B$ virus $X$ protein $(\mathrm{HBX})$ promotes apoptosis in tubular epithelial cells. In this study, we transfected podocytes with $\mathrm{HBx}$ and examined the effects on adhesion and apoptosis of these cells. Methods: Podocytes were transfected with pcDNA3.1 (+)-HBx. One control group was not transfected and another control group was transfected with empty plasmids. Podocyte adhesion was assessed by a fluorescence assay, apoptosis was measured by flow cytometry and fluorescence microscopy, and expression of $\alpha 3 \beta 1$ integrin was determined by western blotting and the reverse transcription polymerase chain reaction (RT-PCR). Activity of caspase- 8 was measured by a spectrophotometric assay. Results: Relative to controls, podocytes with pc-DNA3.1(+)-HBx had reduced cell adhesion, increased apoptosis, reduced expression of $\alpha 3 \beta 1$ integrin, and increased caspase- 8 activity. $\beta 1$ integrin blockage reduced podocyte adhesion, but increased apoptosis and caspase- 8 activity. Treatment of transfected podocytes with a caspase-8 inhibitor (Z-IETD-FMK) had no effect on the $\mathrm{HBx}$-mediated integrin downregulation and reduced podocyte adhesion, suggesting that $\alpha 3 \beta 1$ integrin downregulaton is sufficient to alter cell adhesion. Conclusions: Our in vitro results indicate that $\mathrm{HBx}$ reduced podocyte adhesion and expression of $\alpha 3 \beta 1$ integrin, and increased apoptosis. Moreover, $\mathrm{HBX}$-mediated downregulation of $\alpha 3 \beta 1$ integrin expression is sufficient to reduce podocyte adhesion. $\mathrm{HBx}$-induced apoptosis of podocytes may contribute to HBV-GN.

\section{Introduction}

Approximately 350 million individuals worldwide have chronic hepatitis B virus (HBV) infections [1]. HBV infection rates vary remarkably by geographical area, and the prevalence is particularly high in China, Southeast Asia, and Africa. HBV infection is currently a 
significant public health problem in China [2]. A variety of extrahepatic manifestations, one of the commonest being HBV-associated nephropathy, may develop in individuals with chronic HBV infections [3]. HBV is also a well known cause of membranous nephropathy (MN) [3]. In addition, several other forms of renal disease, including membranoproliferative glomerulonephritis (MPGN), IgA nephropathy, and rarely focal segmental glomerular sclerosis (FSGS), are associated with HBV infection [3].

Recent studies indicated that the number and density of podocytes decrease significantly in patients with HBV-MN, and that this decrease accompanies an increase in the excretion of urinary protein [4]. Thus, the reduction in the number of podocytes seems to play an important role in the pathogenesis of HBV-MN [4]. Podocytes are highly differentiated terminal cells that extrude foot processes which wrap the glomerular basement membrane (GBM). These foot processes connect via tight junctions and form the last barrier of glomerular filtration. Thus, a reduced number of podocytes leads to proteinuria. Apoptosis, compromised adhesion of podocytes, and shedding from the GBM are the major causes of the reduced number of podocytes [5-8]. Integrins are transmembrane receptors that have a major role in the attachment of podocytes to the GBM and in the regulation of cell apoptosis $[7,9]$. Downregulation of podocyte $\alpha 3 \beta 1$ integrin occurs in diverse glomerular disorders in humans and experimental animal models of renal diseases [10]. However, changes in integrin expression have never been studied in HBV-associated glomerulonephritis (HBV-GN).

Sakai reported a case of focal segmental glomerulosclerosis (FSGS) with HBV infection, in which HBV-DNA occurred in urinary podocytes, based on real-time PCR [3]. After administration of anti-viral therapy, the FSGS resolved and this coincided with a decreased level of HBV DNA in podocytes. This was the first report to document HBV infection of podocytes. These findings indicate that HBV infection can reduce the adhesion of podocytes to the GBM and lead to shedding from the GBM. The HBV genome contains 4 overlapping open reading frames that encode the viral envelope, capsid, polymerase/reverse transcriptase, and nonstructural $\mathrm{X}(\mathrm{HBx})$ proteins. $\mathrm{HBx}$ is a multifunctional protein that regulates numerous signal transduction pathways, including those that modulate apoptosis [1].

Our previous study showed that HBx plays an important role in the pathogenesis of HBVGN, in that it activates the JAK2/STAT3 signaling pathway and induces apoptosis of tubular epithelial cells [2]. However, the effects of HBx on the apoptosis and adhesion of podocytes are still uncertain. In the present study, we examined the mechanism of the effects of HBx on podocytes. Thus, we transfected pcDNA3.1(+) HBx into podocytes and evaluated adhesion of podocytes, apoptosis, and $\alpha 3 \beta 1$ integrin expression in transfected cells relative to controls.

\section{Materials and Methods}

\section{Cell culture}

A conditionally immortalized mouse podocyte cell line was kindly provided by Dr. Lin, Dalian Medical University (Dalian, China). Cells were cultured and maintained in RPMI-1640 medium that was supplemented with $10 \%$ fetal bovine serum (FBS), $0.1 \mathrm{mg} / \mathrm{mL}$ streptomycin, $100 \mathrm{U} / \mathrm{mL}$ penicillin, and $10 \mathrm{U} /$ $\mathrm{mL}$ interferon- $\gamma$ at a "permissive" temperature of $33^{\circ} \mathrm{C}$ with $5 \%$ carbon dioxide. When cells reached $80-90 \%$ confluence, they were trypsinized, and differentiation was induced under "restrictive" conditions (absence of interferon $-\gamma$ at $37^{\circ} \mathrm{C}$ for 2 weeks). Experimental procedures were conducted in the same medium without interferon- $\gamma$.

Human lung adenocarcinoma epithelial cells (A549) were used as a source of laminin-10/11, as previously described $[9,11]$. These cells were cultured in DMEM medium that was supplemented with 100 $\mathrm{U} / \mathrm{mL}$ penicillin, $0.1 \mathrm{mg} / \mathrm{mL}$ streptomycin, and $10 \%$ fetal bovine serum (FBS).

\section{Plasmid construction and transfection}

The plasmid pcDNA3.1(+)-HBx was constructed as previously reported [12]. Some experiments had three treatment groups: (i) control (no transfection); (ii) transfection with empty pc-DNA3.1(+) plasmid; and (iii) transfection with pc-DNA3.1(+)-HBx and evaluated after $48 \mathrm{~h}$. Lipofectamine ${ }^{\mathrm{TM}}$ LTX $_{\text {and PLUS }}^{\mathrm{TM}}$ transfection reagents (Invitrogen, USA) were used to conduct the transfection according to the steps 


\section{Cellular Physiology Cell Physiol Biochem 2017;41:689-700 \begin{tabular}{ll|l} 
DOI: 10.1159/000458428 & O 2017 The Author(s). Published by S. Karger AG, Basel \\
and Biochemistry & Published online; ;-ebruary 08, 2017 www.karger.com/cpb
\end{tabular} \\ He et al.: HBx Reduces Podocyte Adhesion}

described in the instructions. For transfection experiments, cells were seeded at $2 \times 10^{5} / \mathrm{mL}$, transfected with equal amounts of DNA, and collected at $48 \mathrm{~h}$. All experiments were repeated three times.

\section{Cell adhesion assay}

Ninety-six-well plates were coated with human placental collagen IV $\left(30 \mu \mathrm{g} / \mathrm{cm}^{2}\right)$ over a 2-h period at $37^{\circ} \mathrm{C}$. For laminin coating, A549 cells were seeded $\left(3 \times 10^{4}\right.$ cells/well) to near confluence, maintained in culture at confluence for 3 days, and subsequently lysed with $0.1 \mathrm{~mol} / \mathrm{L} \mathrm{NH}_{4} \mathrm{OH}$, as previously described $[9,11]$. Post-coating, the plates were washed with PBS and blocked for $30 \mathrm{~min}$ at $37^{\circ} \mathrm{C}$ with $1 \% \mathrm{BSA}$ in PBS. A cell adhesion quantification kit based on fluorescence (Calbiochem, San Diego, CA, USA) was used to detect podocyte adhesion as previously described, with small modifications $[9,11,13]$. After different interventions, podocytes were re-suspended in FBS-free RPMI- 1640 at a density of $2 \times 10^{5}$ cells $/ \mathrm{mL}$, seeded into 96-well plates $\left(100 \mu \mathrm{L} /\right.$ well, and then incubated at $37^{\circ} \mathrm{C}$ with $5 \% \mathrm{CO}_{2}$ for $3 \mathrm{~h}$. The medium was removed, and cells were washed twice with PBS $(200 \mu \mathrm{L} /$ well). Then, a Calcein-AM working solution $(100 \mu \mathrm{L})$ was added, followed by incubation at $37^{\circ} \mathrm{C}$ with $5 \% \mathrm{CO}_{2}$ for $1 \mathrm{~h}$. The relative fluorescence units (RFUs) were determined with a microplate reader (excitation wavelength: $485 \mathrm{~nm}$, emission wavelength: $520 \mathrm{~nm}$ ).

A standard curve was run in each experiment as an internal control. Results are expressed as percentage change relative to the control. All experiments were conducted at least 3 times (10 wells per group), and means were calculated for statistical analysis.

\section{Apoptosis}

The morphology of apoptotic cells was observed by staining the nuclei with H033342 (Sigma, USA). Cell slides were taken out, washed 3 times with PBS, fixed with $4 \%$ paraformaldehyde for 20 min, and washed 3 times again with PBS. After H033342 fluorochrome (5 mg/L) was added, the slides were incubated for $8 \mathrm{~min}$ at $37^{\circ} \mathrm{C}$ while protected from light, and then rewashed 3 times with PBS. Observations and imaging were immediately conducted under a fluorescence microscope. Two hundred cells were counted on each coverslip, and all cells were classified as normal (nuclei with smooth and defined boundaries) or apoptotic (nuclei with condensed or fragmented chromatin).

The percentage of apoptotic cells was determined by flow cytometry using an FITC Annexin V Apoptosis Detection kit (Nanjing KGI Biotechnology Development Co., Ltd., China). Cells were stained according to the manufacturer's instructions, and flow cytometry was conducted using a FACScan flow cytometer (Becton Dickinson, San Jose, CA, USA). Cells in early apoptosis were defined as those with Annexin V-positivity and PI-negativity; cells in late apoptosis were defined as those with Annexin V-positivity and PI-positivity. The results show the sums of early and late apoptosis.

To investigate the relationship of $\alpha 3 \beta 1$ integrin, apoptosis, and cell adhesion, podocytes were exposed to the anti- $\beta 1$ integrin antibody for $30 \mathrm{~min}$, prior to determination of adhesion and measurement of apoptosis.

\section{Measurement of Caspase-8 Activity}

The activity of caspase-8 was measured with the Caspase-8 Activity Assay Kit (Sigma, St. Louis, USA), according to the manufacturer's protocol. In some experiments, a caspase-8 inhibitor (Z-IETD-FMK, 10 $\mu \mathrm{mol} / \mathrm{L}$, [Sigma, St. Louis, USA]) was added into fresh medium with podocytes at $1 \mathrm{~h}$ before transfection with HBx.

\section{Western blotting}

Cells were collected and washed 3 times in cold phosphate-buffered saline and combined with cell lysis buffer $(50 \mathrm{mM}$ Tris-Cl, $\mathrm{pH} 7.4,150 \mathrm{mM} \mathrm{NaCl}, 0.5 \%$ sodium deoxycholate, $1 \% \mathrm{NP}-40,0.1 \%$ sodium dodecyl sulfate [SDS], $1 \mathrm{mM}$ EDTA, $100 \mathrm{mM} \mathrm{NaF}, 1 \mathrm{mM} \mathrm{Na}_{3} \mathrm{VO}_{4}, 1 \mathrm{mM}$ phenylmethylsulfonyl fluoride, $2 \mu \mathrm{g} / \mathrm{mL}$ aprotinin) on ice for $30 \mathrm{~min}$. Cell lysates were centrifuged at $12,000 \mathrm{rpm}$ at $4^{\circ} \mathrm{C}$ for $20 \mathrm{~min}$, and supernatants were stored at $-80^{\circ} \mathrm{C}$. Total protein concentration in the supernatant was determined by the bicinchoninic acid (BCA) protein assay. Protein samples were electrophoresed on a graded SDS/polyacrylamide gel under reducing conditions, transferred onto a nitrocellulose membrane, blocked in 5\% non-fat dried milk in Trisbuffered saline with Tween, and incubated overnight at $4^{\circ} \mathrm{C}$ with the primary antibodies (anti-HBx antibody [Chemicon,Temecula, USA], anti-heavy chain of integrin $\alpha 3$ [BD Biosciences, Oxford, UK], anti- integrin $\beta 1$ [Cell Signaling Technology, Beverly,USA]). After washing, a secondary antibody was added and incubated 
Table 1. Nucleotide sequences of the primers used for real-time PCR. PCR=polymerase chain reaction

\begin{tabular}{lll}
\hline Genes & Forward $\left(5^{\prime}-3^{\prime}\right)$ & Reverse $\left(5^{\prime}-3^{\prime}\right)$ \\
\hline$\alpha 3$ integrin & CCCTCGCTTTGTAGGTTA & GTCCCTGTCAGCCTCCACT \\
$\beta 1$ integrin & GACCTGCCTTGGTGTCTGTGC & AGCAACCACACCAGCTACAAT \\
$\beta$-actin & GGAGATTACTGCCCTGGCTCCTA & GACTCATCGTACTCCTGCTTGCTG \\
\hline
\end{tabular}

for $1 \mathrm{~h}$ at room temperature. Protein bands were visualized using ECL Plus (Thermo Scientific). Membranes were also treated with an anti- $\beta$-actin antibody (Santa Cruz, CA, USA) as an internal loading control.

Real-time reverse transcription polymerase chain reaction

Total RNA was isolated from cells using the Trizol reagent according to the manufacturer's protocol (Takara Biotechnology, Dalian, China). Complementary DNA (cDNA) was synthesized from total RNA by reverse transcription (RT) using a high-capacity cDNA archive kit (Takara Biotechnology, Dalian, China), according to the manufacturer's instructions. Primers for PCR that targeted $\alpha 3$ integrin, $\beta 1$ integrin, and $\beta$-actin genes were designed using the corresponding GenBank sequences, and were synthesized by Takara Biotechnology (Dalian, China) (Table 1). Targets were amplified by real-time RT-PCR using a TaKaRa realtime PCR kit on an ABI 7500 Sequence Detection System (Applied Biosystems, Foster City, CA, USA). Quantitation of mRNA was determined from the threshold PCR cycle number at which exponential growth of the PCR product was detectable. The mRNA level in each sample was normalized to that of $\beta$-actin.

Statistical analysis

All results are expressed as means \pm standard deviations (SDs) and analyzed with SPSS version 15.0. Results were compared using ANOVA. When ANOVA indicated a statistically significant difference, multiple comparisons was performed using Tukey. A p-value less than 0.05 was considered statistically significant.

\section{Results}

Transfected podocytes express $H B x$

Western blotting indicated the presence of a 17-kD band (corresponding to $\mathrm{HBx}$ ) in podocytes transfected with pc-DNA3.1(+)-HBx (Fig. 1A, B). Both control groups (no transfection, transfection with empty plasmid) had no HBx expression.

\section{HBx downregulates $\alpha 3 \beta 1$ integrin}

Next, we used western blotting to examine the expression of $\alpha 3 \beta 1$ integrin to assess the possible link between integrins, cell adhesion, and apoptosis. The results indicate that cells transfected with HBx had significantly lower expression of $\alpha 3 \beta 1$ integrin than cells in both control groups (Fig. 2A, B). RT-PCR analysis of $\alpha 3 \beta 1$ integrin mRNA also indicated lower expression in cells transfected with HBx than in both control groups (Fig. 2C).

\section{HBx induces apoptosis}

We also examined the effect of HBx on apoptosis by use of fluorescence microscopy, flow cytometry, and measurement of caspase- 8 activity (a key protein in apoptosis). The results indicate chromatin condensation and nuclear fragmentation in cells transfected with $\mathrm{HBx}$ (Fig. 3A), but not in both control groups. The flow cytometry results provide quantitation of the effect of HBx on apoptosis (Fig. 3B). These results show low percentages of apoptotic cells in both control groups (no transfection: $3.31 \% \pm 1.12$, transfection with empty plasmid: $2.22 \% \pm 0.93)$. In contrast, $25.36 \%( \pm 3.01)$ of cells transfected with HBx were apoptotic at $48 \mathrm{~h}$ (Fig. 3B, C). Cells transfected with HBx also had upregulated caspase-8 activity $(38.13 \%$ \pm 2.19 ) relative to no transfection cells (Fig. 4).

\section{HBx reduces cell adhesion}

We measured podocyte adhesion in the same 3 groups of cells using a fluorescence assay. The results indicate that podocyte adhesion was significantly reduced $(26.2 \% \pm$ $2.48 \%$ ) in cells transfected with HBx relative to no transfection cells (Fig. 5). 


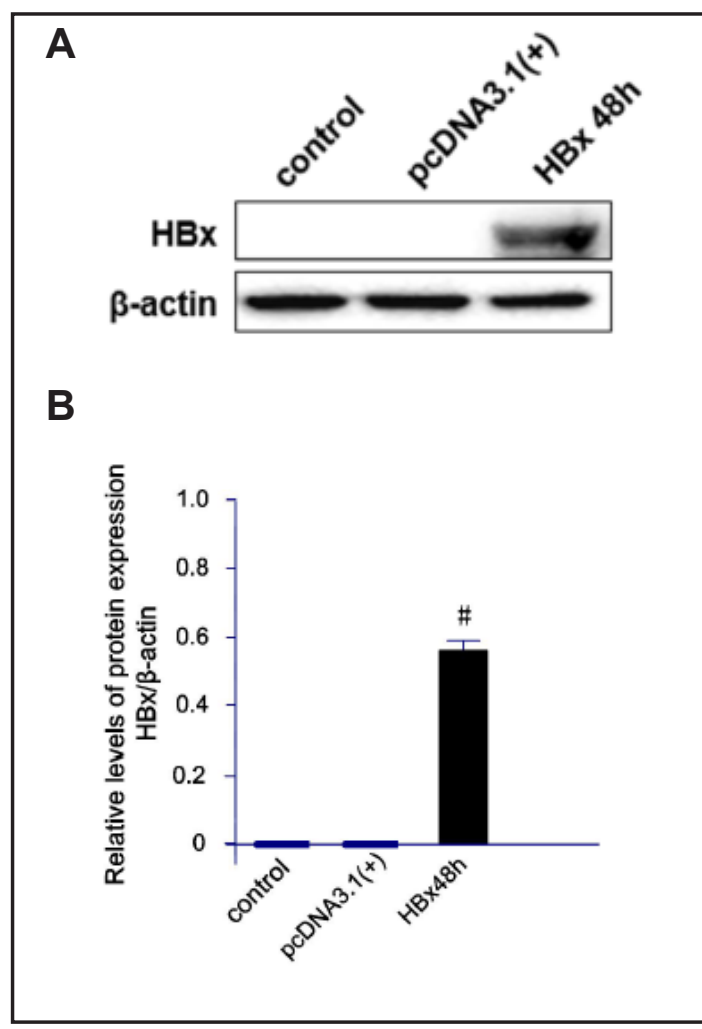

Fig. 1. (A) Representative western blots of $H B x$ in the 2 control groups (no transfection, transfection with empty pc-DNA3.1 $(+)$ plasmid), and cells transfected with pc-DNA3.1(+)-HBx. (B) Quantitation of western blotting results. ${ }^{\#} p<0.05$ relative to the 2 controls. HBx: hepatitis B virus X protein.

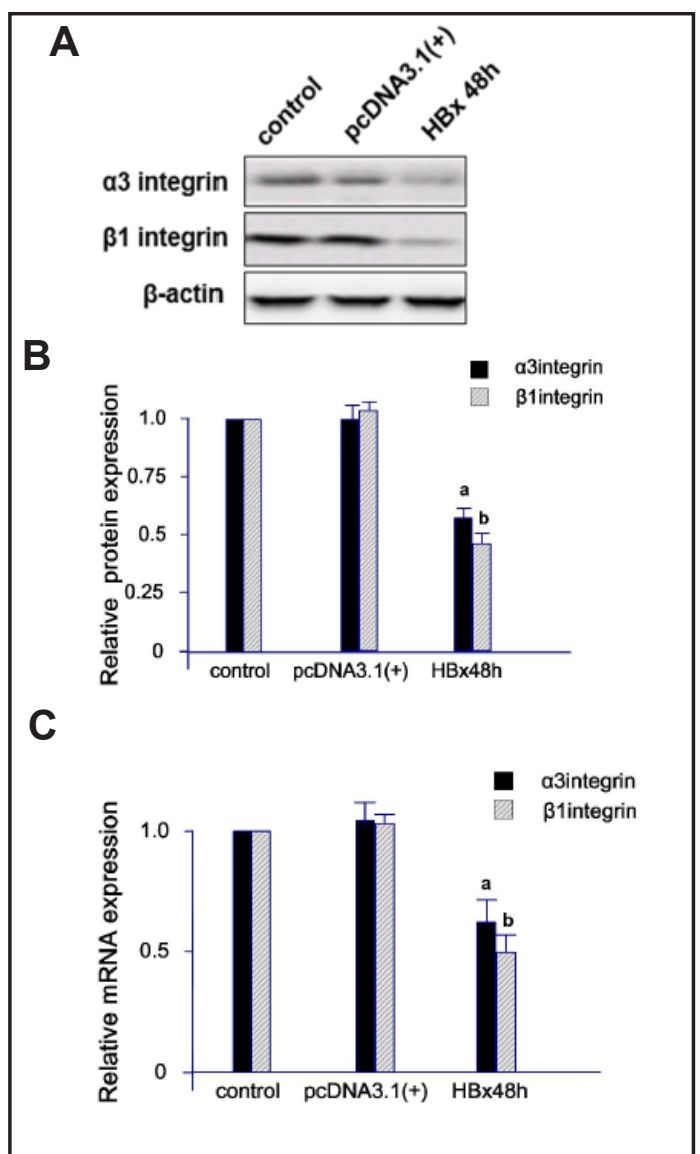

Fig. 2. (A) Representative western blotting of $\alpha 3$ integrin and $\beta 1$ integrin in the 2 control groups (no transfection, transfection with empty plasmid) and cells transfected with HBx. (B) Quantitation of western blotting results. ${ }^{\mathrm{a}, \mathrm{b}} p<0.05$ relative to the 2 controls. (C) Quantitation of RT-PCR results. ${ }^{\mathrm{a}, \mathrm{b}} p<0.05$ relative to the 2 controls.

\section{Inhibition of $\beta 1$ integrin increases apoptosis and decreases cell adhesion}

To confirm the link between $\beta 1$-integrin, adhesion, and apoptosis, we treated transfected podocytes with a specific $\beta 1$-integrin antibody. The results indicate that blocking of $\beta 1$ integrin in cells transfected with HBx led to a significant reduction in podocyte adhesion $(34.3 \% \pm 2.35, p<0.05)$ (Fig. $6 \mathrm{~A}$ ), a significant increase in apoptosis as measured by flow cytometry $(24.2 \% \pm 1.86, p<0.05)$, and increased caspase-8 activity (Fig. $6 \mathrm{~B})$.

Caspase-8 inhibition does not affect HBx-induced downregulation of integrin and cell adhesion

We treated podocytes with a caspase-8 blocker (Z-IETD-FMK, BioVision, San Francisco, CA, USA) to further elucidate the relationship between increased podocyte apoptosis and reduced podocyte adhesion in cells transfected with $\mathrm{HBx}$. In cells that were not transfected, this inhibitor reduced caspase- 8 activity by $\sim 30 \%(p<0.05)$, but it did not affect the expression of $\alpha 3 \beta 1$ integrin or podocyte adhesion (Fig. 7A-C). This inhibitor also reduced caspase-8 activity and apoptosis in cells transfected with HBx (Fig. 7D-E), but had no effect on the downregulation of $\alpha 3 \beta 1$ integrin (Fig. 8A-C). The adhesion of HBx-transfected cells was similar in the presence or absence of the caspase-8 inhibitor (Fig. 9). These findings suggest that the HBx-induced reduction in podocyte adhesion is associated with reduced expression of $\alpha 3 \beta 1$ integrin, but not with HBx-induced apoptosis. In other words, inhibition 
Fig. 3. (A) Nuclear staining (Hoechst 33342) and fluorescence microscopy $(\times 400)$ of the 2 controls (no transfection, transfection with an empty plasmid) and cells transfected with HBx. (B) Flow cytometry of apoptosis in each group. (C) Quantitation of the flow cytometry results. Abscissa presents cell groups and ordinate presents apoptosis rate of the various groups. ${ }^{a} p<$ 0.05 relative to the 2 controls.

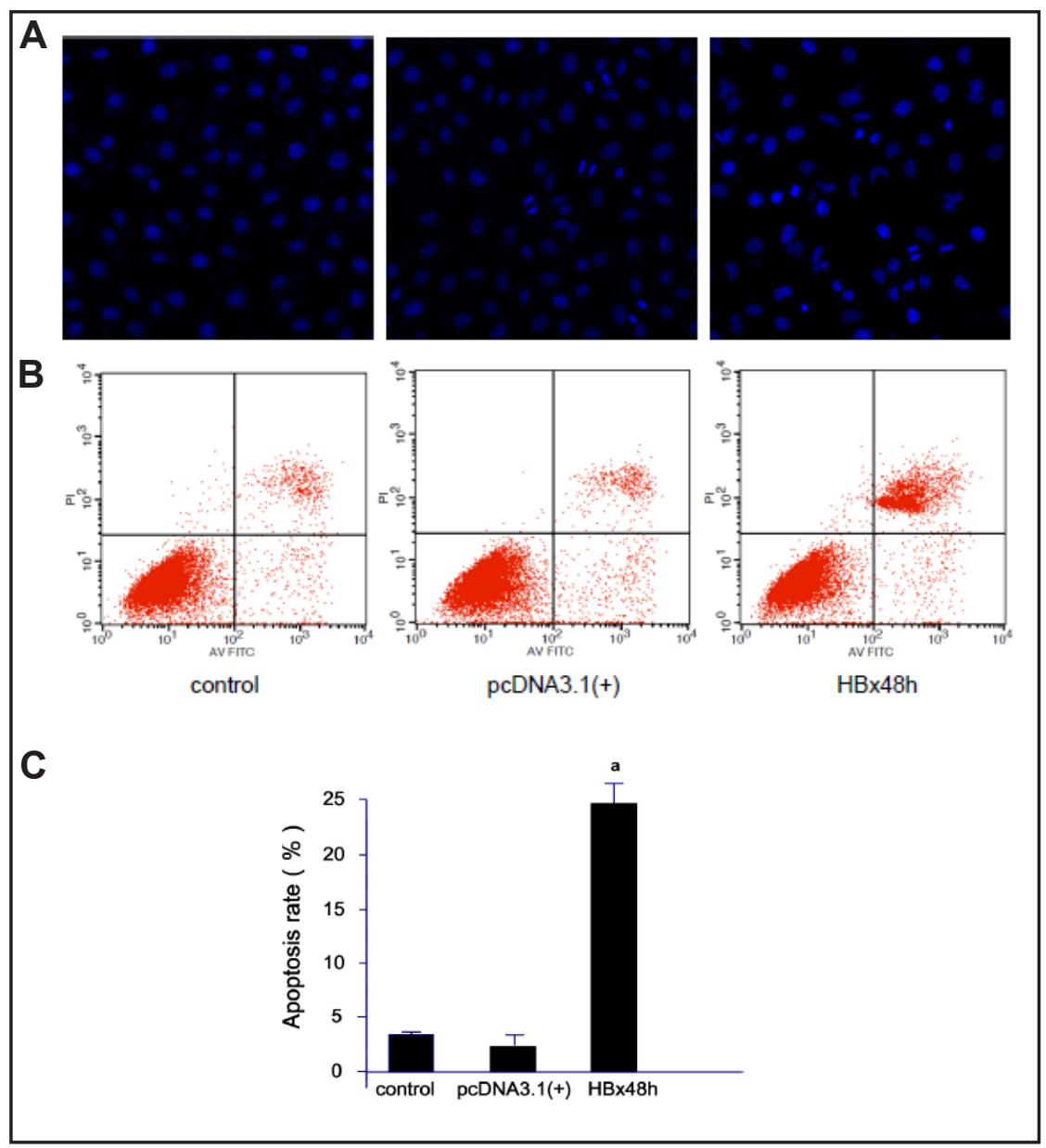

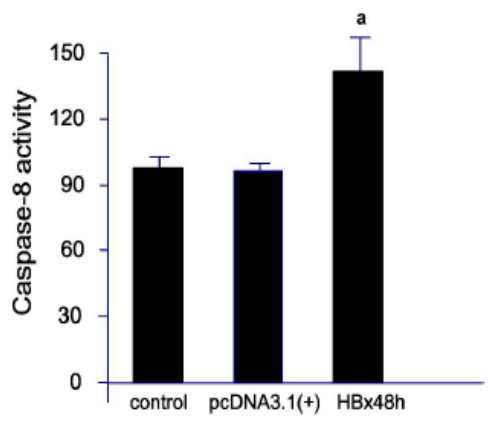

Fig. 4. Activity of caspase-8 in control cells (no transfection, transfection with empty plasmid) and cells transfected with HBx. Caspase-8 activity is expressed as a percentage of no transfection cells. ${ }^{\mathrm{a}} p<$ 0.05 relative to the 2 controls.

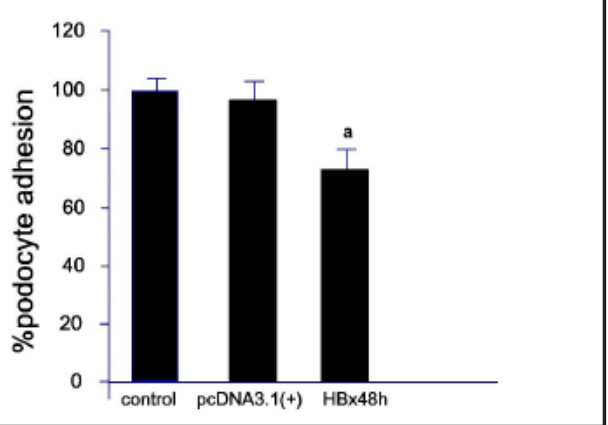

Fig. 5. Adhesion to an extracellular matrix substrate in control cells (no transfection, transfection with an empty plasmid) and cells transfected with HBx. Cell adhesion is expressed as a percentage of no transfection cells. ${ }^{a} p<0.05$ relative to the 2 controls.

of HBx-induced apoptosis in podocytes had no effect on the reduced adhesion of these cells.

\section{Discussion}

Proteinuria is a well-known symptom of injury to the glomerular filtration barrier. Podocytes play a crucial role in maintaining the permeability of the glomerular filtration 


\section{Cellular Physiology Cell Physiol Biochem 2017;41:689-700 \begin{tabular}{ll|l|l} 
DOI: 10.1159/000458428 & $\begin{array}{l}\text { O } 2017 \text { The Author(s). Published by S. Karger AG, Basel } \\
\text { www.karger.com/cpb }\end{array}$ \\
\cline { 2 - 3 }
\end{tabular}

barrier [14], and podocyte injury is present in many types of human and experimental glomerular diseases, including HBV-GN [4, 15-17]. Moreover, a decreased number of podocytes per glomerulus is the strongest predictor of renal disease progression [18]. The reduced number of podocytes may be largely ascribed to their reduced adhesion to the GBM, shedding, and apoptosis. As is well-known, the immune complexes formed by HBV antigens and antibodies have an important role in the pathogenesis of HBVGN. These immune-complexes for deposits in patients with HBV-GN $[19,20]$. Subepithelial immune deposits initiate activation of the complement system of the C3 component, conversion of $\mathrm{C} 5$, and subsequent formation of the $\mathrm{C} 5 \mathrm{~b}-9$ complex in podocyte membranes $[19,21]$. The membrane attack complex (C5b-9) leads to podocyte injury, including calcium influx, oxidative injury, production of arachidonic acid metabolites, cell cycle dysregulation, and endoplasmic reticulum stress [21, 22], These lead to podocyte apoptosis, reduced podocyte adhesion, and detachment of podocytes from GBM, which may result in proteinuria and renal failure $[19,22]$. However, some recent reports that

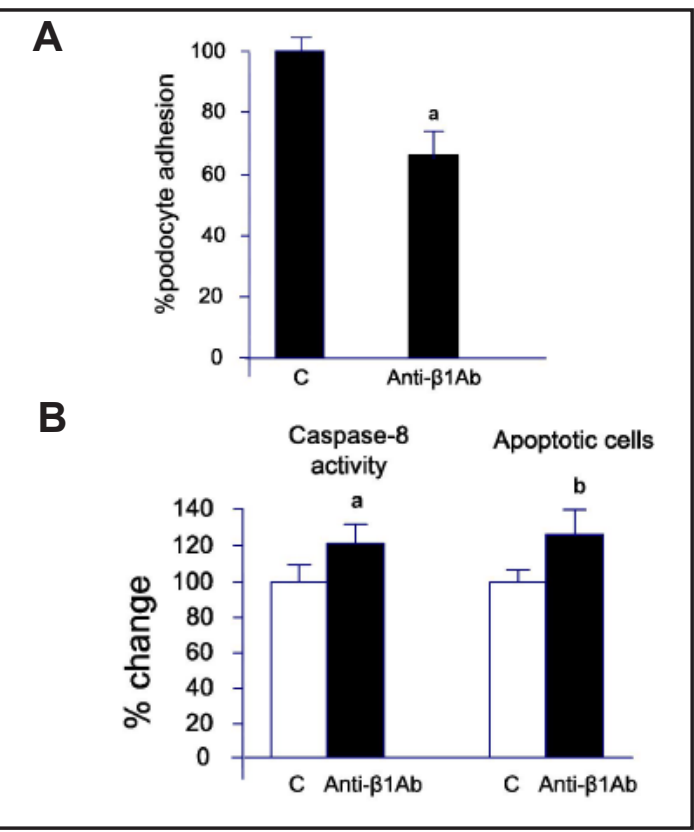

Fig. 6. (A) Effect of anti- $\beta 1$ integrin antibody on podocyte adhesion in cells transfected with HBx. ${ }^{a} p$ $<0.05$ relative to cells transfected with HBx but without anti- $\beta 1$ integrin antibody treatment. (B) Effect of anti- $\beta 1$ integrin antibody on caspase- 8 activity and apoptosis in cells transfected with $\mathrm{HBx} .{ }^{\mathrm{a}, \mathrm{b}} p<$ 0.05 relative to cells transfected with HBx but without anti- $\beta 1$ integrin antibody treatment. identified HBV-DNA, HBV-RNA, and cccDNA in the kidneys suggested that direct virally induced renal damage may also play an important role in the disease process $[3,12,23]$. The focus of the present paper is to examine the direct effect of HBV on podocyte injury and to find the reason for the reduced podocyte numbers in HBV-GN.

Integrins are transmembrane glycoprotein surface receptors composed of $\alpha$ and $\beta$ subunits that are an important component of the extracellular matrix (ECM) [17]. The integrins of the ECM regulate many cell functions, including migration, proliferation, differentiation, cell cycle progression, and survival [24-26]. Recent studies of integrin expression in podocytes demonstrated that $\alpha 3 \beta 1$ integrin is the major integrin on the surface of podocytes in humans [27] and rats [28]. This integrin is responsible for cell adhesion and signal transduction between podocytes and the extracellular matrix (ECM) of the glomerular basement membrane (GBM) [14]. Previous studies have shown that the absolute number and relative density of podocytes are reduced in HBV-GN [4], although the precise mechanism of this effect is unknown. In our previous study of tubular epithelial cells $[2,12]$, we found that HBx inhibited cell proliferation and induced apoptosis. Thus, in the present study, we investigated the effects of HBx on the apoptosis and adhesion of podocytes and the mechanism of this response.

Under normal conditions, we found that $\beta 1$ integrin expression was continuous along the glomerular capillary loop, consistent with previous reports $[29,30]$. However, there is reduced expression of $\alpha 3 \beta 1$ integrin in the podocytes of humans with FSGS [31], in humans and rats with diabetes [32], and in rats treated with puromycin aminonucleoside (PAN) [33]. However, the function of integrin in podocytes transfected with HBx has not been studied to date. We had no way to get the human immortalized podocytes within a short time for the limitations of resource, funds and technology. And we were pressed for time, so we used mouse podocytes in the present study. We employed real time RT-PCR and immunoblotting 
Fig. 7. (A) Caspase-8 activity and podocyte adhesion in the presence of vehicle (Veh) or a caspase-8 inhibitor (Inh) in cells with no transfection. ${ }^{a} p<0.05$ relative to Veh. (B, C) Representative western blots of $\alpha 3$ integrin and $\beta 1$ integrin in the presence of Veh or Inh in cells with no transfection, and quantitation of these results. (D, E) Caspase-8 activity and apoptosis in control cells (no transfection, transfection with an empty plasmid), cells transfected with $\mathrm{HBx}$, and cells transfected with $\mathrm{HBx}$ and treated with Inh. Data are presented as percentage change from control (no transfection and without a caspase-8 inhibitor). ${ }^{\mathrm{a}} p<0.05$ relative to controls (no transfection and without a caspase-8 inhibitor, transfection with an empty plasmid and without a caspase-8 inhibitor). ${ }^{\mathrm{b}} p<0.05$ relative to cells transfected with $\mathrm{HBx}$ and without a caspase-8 inhibitor.

assays to examine $\alpha 3 \beta 1$ integrin expression in mouse podocytes that express HBx. The results indicate that as early as $48 \mathrm{~h}$ after transfection, there is decreased expression of $\alpha 3 \beta 1$ integrin and reduced podocyte adhesion. These results are consistent with previous studies of podocytes, and suggest a link between integrin expression and cell adhesion. In particular, previous studies reported that downregulation of $\alpha 3 \beta 1$ integrin is causally related to the loss of podocytes [31-33]. This is supported by our recent observations (He, Ping et al., unpublished data), in which we found podocytes in the urinary sediment of patients with HBV-GN and a parallel reduction in the number of podocytes in renal biopsy tissue. To elucidate the relationship between $\beta 1$ integrin expression and podocyte adhesion, we treated podocytes with a $\beta 1$ integrin inhibitor. The results showed that this inhibitor significantly reduced podocyte adhesion, and therefore suggest a relationship between $\beta 1$ integrin expression and podocyte adhesion. Apoptosis is another major cause of the reduced number of podocytes in diverse renal diseases. For example, increased apoptosis of podocytes occurs in diseased glomeruli and may be responsible for cell loss in glomerulosclerosis $[34,35]$.

HBx appears to be a multifunctional protein that can activate signaling pathways in various cell types, regulate cell proliferation, and induce apoptosis [36-38].

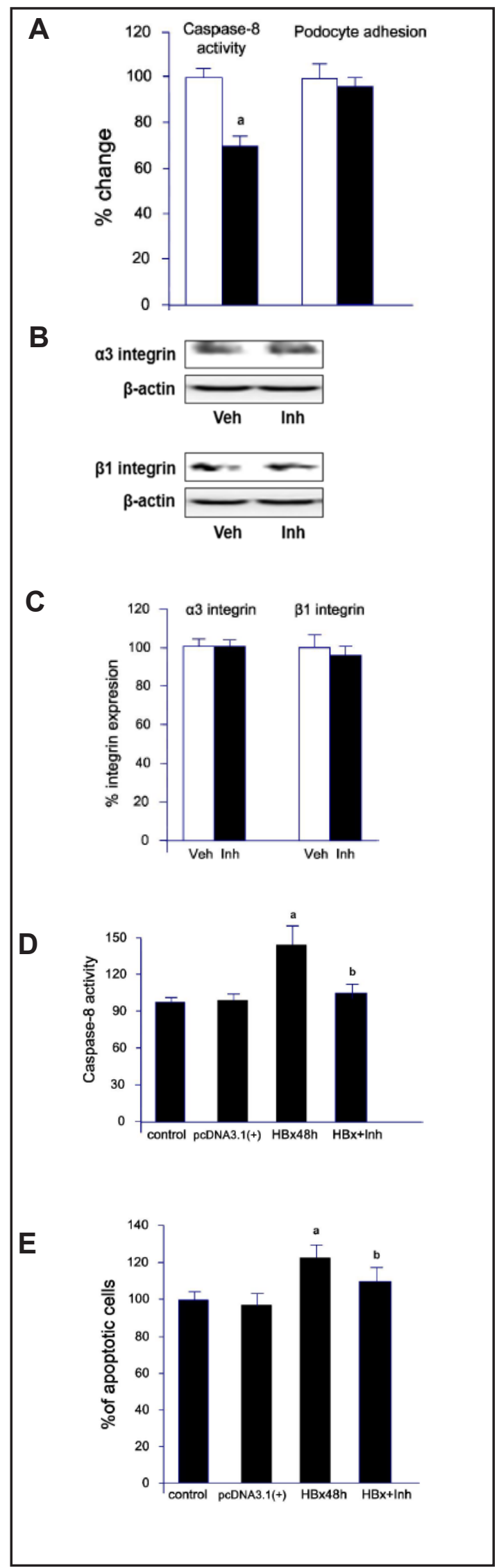


Fig. 8. Effect of caspase-8 inhibition (Inh) on integrin expression in control cells (no transfection, transfection with an empty plasmid) and cells transfected with HBx. Inh treatment did not affect HBx-mediated down-regulation of $\alpha 3$ and $\beta 1$ integrin. (A) Representative western blotting of $\alpha 3$ integrin and $\beta 1$ integrin in the presence of vehicle (Veh) or a caspase-8 inhibitor (Inh) in control cells (no transfection, transfection with an empty plasmid) and cells transfected with HBx. (B-C) Quantitation of these results. ${ }^{a} p<0.05$ relative to the 2 controls for Veh-treated cells; ${ }^{\mathrm{b}} p<0.05$ relative to the 2 controls for Inh-treated cells.

The mechanism by which $\mathrm{HBx}$ regulates apoptosis seems to vary according to cell type and environment [1]. Some research indicates that HBx transfection limits the proliferative capacity of podocytes through cell cycle regulation [39]. However, the effect of HBx on apoptosis of podocytes and the specific underlying mechanism are still poorly understood. Integrin can have prosurvival or proapoptotic effects on cells [40]. A connection between $\alpha 3 \beta 1$ integrin and apoptosis of podocytes is supported by the recent work of Chen et al. [7], who showed that $\alpha 3 \beta 1$ integrin antagonists increased the apoptosis of podocytes and increased the levels of several markers of apoptosis. Our findings showed that podocytes transfected with $\mathrm{HBx}$ had reduced expression of $\alpha 3 \beta 1$ integrin, increased apoptosis, and increased caspase-8 activity.

We treated podocytes with an integrin $\beta 1$ inhibitor to elucidate the relationship of downregulation of $\alpha 3 \beta 1$ integrin with increased apoptosis and reduced adhesion. The results showed that this inhibitor significantly increased podocyte apoptosis and reduced adhesion relative to the controls. This confirms that reduced $\beta 1$ integrin expression is related to increased apoptosis and reduced adhesion. We further investigated the role of apoptosis in podocyte adhesion by treating podocytes transfected with $\mathrm{HBx}$ with a caspase-8 inhibitor. Interestingly, this inhibitor did not affect HBx-induced downregulation of $\alpha 3 \beta 1$ integrin or the HBx-induced decline in cell adhesion. This suggests that downregulation of $\alpha 3 \beta 1$ integrin by itself is sufficient to alter cell adhesion, and that activation of apoptosis

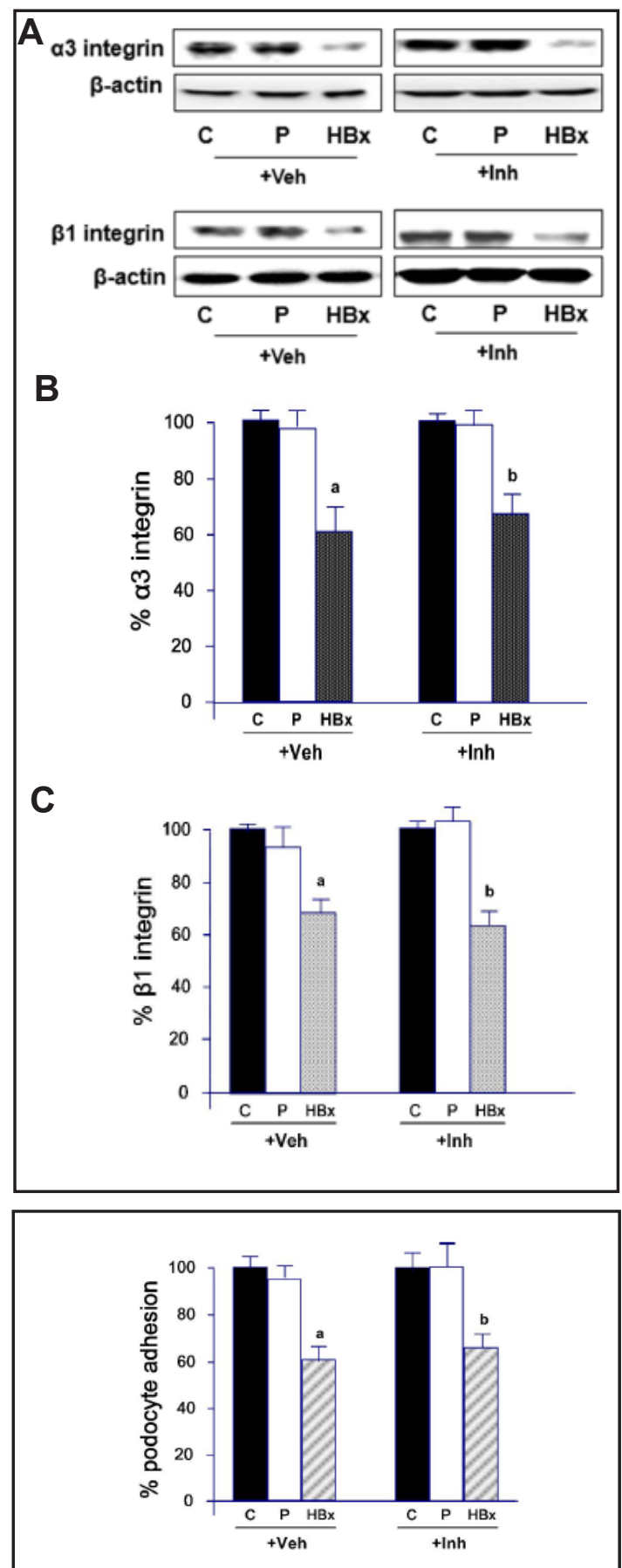

Fig. 9. Effect of caspase-8 inhibition (Inh) on podocyte adhesion in control cells (no transfection, transfection with an empty plasmid) and cells transfected with HBx. Inh treatment had no effect on HBx-mediated reduction of podocyte adhesion. Data are presented as percentage change from control (no transfection and no Inh). ${ }^{\mathrm{a}} p<0.05$ relative to controls (no transfection, transfection with an empty plasmid, and Veh); ${ }^{\mathrm{b}} p<0.05$ relative to controls (no transfection, transfection with an empty plasmid, and Inh). 
is not necessary for the loss of podocyte adhesion. However, a loss of integrin binding to ECM substrates (complete cell detachment) may favour the process of anoikis and trigger frank apoptosis $[9,41]$. Reduced adhesion-induced apoptosis may have a crucial role on the fate of detaching podocytes [9]. In other words, HBx-induced podocyte apoptosis may be downstream of decreased cell adhesion.

In conclusion, this study found that HBx reduces the adhesion and increases the apoptosis of podocytes. HBx also reduced expression of $\alpha 3 \beta 1$ integrin, and the downregulation of $\alpha 3 \beta 1$ integrin is sufficient to reduce podocyte adhesion. HBx-induced podocyte apoptosis may be a downstream effect of decreased cell adhesion, although we cannot exclude the possibility that downregulation of $\alpha 3 \beta 1$ integrin directly induces podocyte apoptosis. We suggest that future work should seek to further understand these relationships. Our results strongly suggest that $\mathrm{HBx}$ is involved in the HBV-induced injury of podocytes. A limitation of this study is that we did not directly examine the molecular mechanism underlying the HBXinduced down-regulation of integrin. Our future work will investigate the mechanism by which HBx causes down-regulation of integrin $\alpha 3 \beta 1$, and will attempt to extend these studies to in vivo models.

\section{Acknowledgements}

This study was supported by the Education Commission of Liaoning Province of China (grant no. L2013295) and Dr. start fund of Liaoning Province of China (grant no. 201501005).

\section{Disclosure Statement}

The results presented in this paper have not been published previously in whole or part, except in abstract format. The authors declare that there are no conflicts of interest.

\section{References}

1 Clippinger AJ, Gearhart TL, Bouchard MJ: Hepatitis B virus X protein modulates apoptosis in primary rat hepatocytes by regulating both NF-kappaB and the mitochondrial permeability transition pore. J Virol 2009;83:4718-4731.

- He P, Zhang D, Li H, Yang X, Li D, Zhai Y, Ma L, Feng G: Hepatitis B virus X protein modulates apoptosis in human renal proximal tubular epithelial cells by activating the JAK2/STAT3 signaling pathway. Int J Mol Med 2013;31:1017-1029.

- 3 Sakai K, Morito N, Usui J, Hagiwara M, Hiwatashi A, Fukuda K, Nanmoku T, Toda T, Matsui N, Nagata M, Yamagata K: Focal segmental glomerulosclerosis as a complication of hepatitis B virus infection. Nephrol Dial Transplant 2011;26:371-373.

4 Zhang Y, Zhou JH, Wang HT: [Podocyte depletion in children with hepatitis B virus-associated membranous nephropathy]. Zhonghua Er Ke Za Zhi 2007;45:344-348.

5 Vogelmann SU, Nelson WJ, Myers BD, Lemley KV: Urinary excretion of viable podocytes in health and renal disease. Am J Physiol Renal Physiol 2003;285:F40-48.

6 Grossmann J: Molecular mechanisms of "detachment-induced apoptosis--Anoikis". Apoptosis 2002;7:247260.

7 Chen CA, Tsai JC, Su PW, Lai YH, Chen HC: Signaling and regulatory mechanisms of integrinalpha3beta1 on the apoptosis of cultured rat podocytes. J Lab Clin Med 2006;147:274-280.

8 Wang B, Xu X, He X, Wang Z, Yang M: Berberine Improved Aldo-Induced Podocyte Injury via Inhibiting Oxidative Stress and Endoplasmic Reticulum Stress Pathways both In Vivo and In Vitro. Cell Physiol Biochem 2016;39:217-228. 


\section{Cellular Physiology Cell Physiol Biochem 2017;41:689-700 and Biochemistry DOI: 10.1159/000458428 2010 P 2017 The Author(s). Published by S. Karger AG, Basel

-9 Dessapt C, Baradez MO, Hayward A, Dei Cas A, Thomas SM, Viberti G, Gnudi L: Mechanical forces and TGFbeta1 reduce podocyte adhesion through alpha3beta1 integrin downregulation. Nephrol Dial Transplant 2009;24:2645-2655.

10 Regoli M, Bendayan M: Alterations in the expression of the alpha 3 beta 1 integrin in certain membrane domains of the glomerular epithelial cells (podocytes) in diabetes mellitus. Diabetologia 1997;40:15-22.

11 Kikkawa Y, Sanzen N, Sekiguchi K: Isolation and characterization of laminin-10/11 secreted by human lung carcinoma cells. laminin-10/11 mediates cell adhesion through integrin alpha3 beta1. J Biol Chem 1998;273:15854-15859.

12 He P, Zhou G, Qu D, Zhang B, Wang Y, Li D: HBx inhibits proliferation and induces apoptosis via Fas/FasL upregulation in rat renal tubular epithelial cells. J Nephrol 2013;26:1033-1041.

$>13$ Dandapani SV, Sugimoto H, Matthews BD, Kolb RJ, Sinha S, Gerszten RE, Zhou J, Ingber DE, Kalluri R, Pollak MR: Alpha-actinin-4 is required for normal podocyte adhesion. J Biol Chem 2007;282:467-477.

14 Liu J, Zhang B, Chai Y, Xu Y, Xing C, Wang X: Fluvastatin attenuated the effect of expression of beta1 integrin in PAN-treated podocytes by inhibiting reactive oxygen species. Mol Cell Biochem 2015;398:207-215.

15 Guerrot D, Dussaule JC, Mael-Ainin M, Xu-Dubois YC, Rondeau E, Chatziantoniou C, Placier S: Identification of periostin as a critical marker of progression/reversal of hypertensive nephropathy. PLoS One 2012;7:e31974.

16 Kretzler M, Koeppen-Hagemann I, Kriz W: Podocyte damage is a critical step in the development of glomerulosclerosis in the uninephrectomised-desoxycorticosterone hypertensive rat. Virchows Arch 1994;425:181-193.

17 Wang G, Lai FM, Kwan BC, Lai KB, Chow KM, Li PK, Szeto CC: Podocyte loss in human hypertensive nephrosclerosis. Am J Hypertens 2009;22:300-306.

18 Pagtalunan ME, Miller PL, Jumping-Eagle S, Nelson RG, Myers BD, Rennke HG, Coplon NS, Sun L, Meyer TW: Podocyte loss and progressive glomerular injury in type II diabetes. J Clin Invest 1997;99:342-348.

19 Lai WL, Yeh TH, Chen PM, Chan CK, Chiang WC, Chen YM, Wu KD, Tsai TJ: Membranous nephropathy: a review on the pathogenesis, diagnosis, and treatment. J Formos Med Assoc 2015;114:102-111.

20 Dettmar AK, Oh J: Infection-Related Focal Segmental Glomerulosclerosis in Children. Biomed Res Int 2016;2016:7351964.

21 Beck LH, Jr., Salant DJ: Membranous nephropathy: from models to man. J Clin Invest 2014;124:2307-2314.

22 Tharaux PL, Huber TB: How many ways can a podocyte die? Semin Nephrol 2012;32:394-404.

-23 Hong L, Zhang J, Min J, Lu J, Li F, Li H, Guo S, Li Q: A role for MHBst167/HBx in hepatitis B virus-induced renal tubular cell apoptosis. Nephrol Dial Transplant 2010;25:2125-2133.

24 Clark EA, Brugge JS: Integrins and signal transduction pathways: the road taken. Science 1995;268:233239.

25 Frisch SM, Ruoslahti E: Integrins and anoikis. Curr Opin Cell Biol 1997;9:701-706.

26 Zhao JH, Reiske H, Guan JL: Regulation of the cell cycle by focal adhesion kinase. J Cell Biol 1998;143:19972008.

-27 Korhonen M, Ylanne J, Laitinen L, Virtanen I: Distribution of beta 1 and beta 3 integrins in human fetal and adult kidney. Lab Invest 1990;62:616-625.

-28 Adler S: Characterization of glomerular epithelial cell matrix receptors. Am J Pathol 1992;141:571-578.

-29 Yuan X, Wang W, Wang J, Yin X, Zhai X, Wang L, Li K, Li Z: Down-regulation of integrin beta1 and focal adhesion kinase in renal glomeruli under various hemodynamic conditions. PLoS One 2014;9:e94212.

-30 Zou MS, Yu J, Zhou JH, Nie GM, Ding DS, Luo LM, Xu HT, He WS: 1,25-Dihydroxyvitamin D3 ameliorates podocytopenia in rats with adriamycin-induced nephropathy. Intern Med 2010;49:2677-2686.

-31 Chen CA, Hwang JC, Guh JY, Chang JM, Lai YH, Chen HC: Reduced podocyte expression of alpha3beta1 integrins and podocyte depletion in patients with primary focal segmental glomerulosclerosis and chronic PAN-treated rats. J Lab Clin Med 2006;147:74-82.

32 Chen HC, Chen CA, Guh JY, Chang JM, Shin SJ, Lai YH: Altering expression of alpha3beta1 integrin on podocytes of human and rats with diabetes. Life Sci 2000;67:2345-2353.

-33 Kojima K, Matsui K, Nagase M: Protection of alpha(3) integrin-mediated podocyte shape by superoxide dismutase in the puromycin aminonucleoside nephrosis rat. Am J Kidney Dis 2000;35:1175-1185.

-34 Shimizu A, Kitamura H, Masuda Y, Ishizaki M, Sugisaki Y, Yamanaka N: Apoptosis in the repair process of experimental proliferative glomerulonephritis. Kidney Int 1995;47:114-121. 


\section{Cellular Physiology Cell Physiol Biochem 2017;41:689-700 \begin{tabular}{ll|l|l|l|l} 
DOI: 10.1159/000458428 & 2017 The Author(s). Published by S. Karger AG, Basel \\
and Biochemistry & Published online: February 08, 2017 www.karger.com/cpb
\end{tabular}}

He et al.: HBx Reduces Podocyte Adhesion

-35 Sugiyama H, Kashihara N, Makino H, Yamasaki Y, Ota A: Apoptosis in glomerular sclerosis. Kidney Int 1996;49:103-111.

-36 Bouchard MJ, Schneider RJ: The enigmatic X gene of hepatitis B virus. J Virol 2004;78:12725-12734.

37 Arbuthnot P, Capovilla A, Kew M: Putative role of hepatitis B virus X protein in hepatocarcinogenesis: effects on apoptosis, DNA repair, mitogen-activated protein kinase and JAK/STAT pathways. J Gastroenterol Hepatol 2000;15:357-368.

-38 Lee YI, Kang-Park S, Do SI, Lee YI: The hepatitis B virus-X protein activates a phosphatidylinositol 3-kinasedependent survival signaling cascade. J Biol Chem 2001;276:16969-16977.

39 Zhang Y, Chen Y, Yang F, Zhou J: HBx transfection limits proliferative capacity of podocytes through cell cycle regulation. Acta Biochim Biophys Sin (Shanghai) 2014;46:1016-1023.

40 Stupack DG, Cheresh DA: Get a ligand, get a life: integrins, signaling and cell survival. J Cell Sci 2002;115:3729-3738.

-41 Grossmann J, Walther K, Artinger M, Kiessling S, Scholmerich J: Apoptotic signaling during initiation of detachment-induced apoptosis ("anoikis") of primary human intestinal epithelial cells. Cell Growth Differ 2001;12:147-155. 